Insignia Journal of International Relations

Vol. 7, No. 2, November 2020, 105-121

P-ISSN: 2089-1962; E-ISSN: 2597-9868

\title{
Upaya Perimbangan Kekuatan Iran-Arab Saudi Melalui Perang Suriah untuk Memenangi Kontestasi Geopolitik di Timur Tengah
}

\author{
Iqbal Ramadhan \\ Jurusan Hubungan Internasional, Universitas Pertamina \\ Email: iqbal.ramadhan@universitaspertamina.ac.id \\ Jodi Alif Iskandar \\ Jurusan Hubungan Internasional, Universitas Pertamina \\ Email: jodialif0407@gmail.com
}

\begin{abstract}
Abstrak
Perang saudara di Suriah terjadi karena perebutan kekuasaan antara pemerintah Bashar Al-Assad dengan tentara pemberontak Suriah. Perang tersebut terjadi tidak hanya melibatkan kekuatan internal Suriah, tetapi juga kekuatan besar yang ada di Timur Tengah yaitu Iran dan Arab Saudi. Perang Suriah dijadikan ajang untuk mengimbangi kekuatan antara Iran dan Arab Saudi melalui proxy mereka. Iran mendukung pemerintah Bashar AlAssad sedangkan Arab Saudi menyatakan dukungan mereka kepada tentara pemberontak. Tujuan dari artikel ini adalah untuk membahas strategi kedua negara dalam mengimbangi kekuatan rivalnya melalui proxy balancing. Konsep proxy balancing sendiri merupakan konsep yang digagas oleh Hans J. Morgenthau untuk menganalisis bagaimana sebuah kekuatan bersaing dengan kekuatan lainnya menggunakan proxy mereka. Metode yang digunakan dalam artikel ini adalah kualitatif dan penulis menggunakan konsep pattern of competition dan konsep geopolitik. Hasil analisis dari artikel ini adalah Iran berusaha untuk mengimbangi kekuatan Arab Saudi untuk memenangkan pengaruh mereka di Timur Tengah melalui sekutu mereka yaitu pemerintah Suriah. Pada saat yang sama, Arab Saudi melakukan hal yang sama untuk mengimbangi Iran dengan memberikan dukungan politik dan militer kepada tentara pemberontak Suriah. Kesimpulan yang didapat dari artikel ini adalah Iran dan Arab Saudi menggunakan proxy mereka pada Perang Suriah untuk mengimbangi kekuatan rivalnya dan memenangkan kontestasi geopolitik di Timur Tengah.
\end{abstract}

Kata kunci: Arab Saudi, geopolitik, Iran, Perang Suriah, perimbangan kekuatan

\begin{abstract}
At the beginning of Syrian Civil War, Syrian government led by Bashar Al-Assad were involved in bloody conflict with Syrian Rebel Forces. This war happened when Syrian Rebel Forces intended to overthrown Assad's corrupt regime. Eventually, this war did not only involved Syrian's domestic power but also major power in the Middle East region such as Iran and Saudi Arabia. Syrian Civil War was an arena to balance the power between Iran and Saudi Arabia. Both the countries used their proxies to achieve their interest. The author used proxy balancing concept from Hans J. Morgenthau to analyze power balancing between great powers by harnessing their proxies. This article aims to analyze the balancing strategy between Iran and Saudi Arabia through their proxies. The author used qualitative method, pattern of competition and geopolitical concept. The author analyzes that both Iran and Saudi Arabia are using their proxies to win geopolitical contestation. Iran supports the existence of Bashar Al-Assad's regime. Meanwhile, Saudi government has given their effort for supporting rebel forces who deny the Assad's regime. The conclusion of this article is that Iran and Saudi Arabia's involvement in Syrian War is intended to balance their power by using proxies and win geopolitical contestation in Middle East.
\end{abstract}

Keywords: balance of power, geopolitics, Iran, Saudi Arabia, Syrian War 


\section{PENDAHULUAN}

Timur Tengah merupakan kawasan yang penuh konflik dan rentan dengan ketidakstabilan. Ibnu Burdah (2008) pernah menyatakan bahwa Timur Tengah adalah daerah yang sepanjang sejarahnya penuh dengan konflik dan kekerasan. Sebagaimana yang Burdah (2008) utarakan dalam bukunya, dimensi konflik yang terjadi di Timur Tengah berkorelasi satu sama lain. Louise Fawcett (2016) menyatakan bahwa Timur Tengah merupakan wilayah yang terbentang dari Maroko di Barat hingga Iran di Timur. Walaupun terdapat negara yang terletak di benua Afrika, Fawcett mengklasifikasikan kesamaan kultur dan agama sebagai salah satu indikator memasukkan negara seperti Maroko, Aljazair, Libya, Mesir dan Sudan sebagai bagian dari studi Timur Tengah (Fawcett, 2016: 40). Institusi internasional seperti OPEC (Organization of Petroleum Exporting Country) menyatakan bahwa $64,5 \%$ cadangan minyak bumi dan gas terdapat di wilayah tersebut (OPEC, 2018). Oleh karenanya, dimensi konflik yang diutarakan oleh Burdah (2008) memang benar adanya karena faktor politik, sosial dan juga ekonomi memainkan peranan penting di dalamnya.

Pada saat ini, konflik Timur Tengah tetap tidak pernah padam. Salah satu konflik yang menjadi perhatian dunia adalah perang sipil di Suriah antara pendukung Bashar Al-Assad dan tentara pemberontak Suriah. Asal mula perang saudara tersebut dipicu dari keresahan sebagian warga Suriah akibat penindasan rezim Bashar Al-Assad (Oktorino, 2015: 1112). Pada akhirnya, keresahan tersebut menjadi pemicu kelompok anti-Assad untuk memerdekakan diri dan menggulingkan rezim tersebut (Oktorino, 2015: 11-12). Mengacu pada data yang dihimpun oleh Syrian Observatory for Human Rights (SOHR) bahwa jumlah korban jiwa akibat Perang Suriah sebanyak 511.000 orag (SOHR, 2018). Korban jiwa tersebut sudah termasuk 11.500 anak-anak yang tewas pada perang sipil tersebut (Robehmed, 2013). Apabila dipandang secara holistik, tidak dapat dimungkiri bahwa terdapat kepentingan besar dua negara superpower di Timur Tengah yaitu Arab Saudi dan Iran (BBC, 2017). Kedua negara tersebut melihat Suriah sebagai wilayah yang memiliki keuntungan secara geopolitik sehingga dua negara tersebut berusaha untuk memainkan pengaruhnya pada Perang Suriah tersebut (BBC, 2017).

Terlepas dari politik domestik yang melingkupi latar belakang terjadinya Perang Suriah, peristiwa ini tidak terlepas dari peranan dua kekuatan besar di Timur Tengah yaitu Iran dan Arab Saudi. Suriah pada hakikatnya adalah salah satu arena bagi kedua negara untuk berebut pengaruh. Dua alasan penting mengapa kedua negara tersebut saling mengimbangi melalui keberadaan proxy adalah influence dan containement (Naghizadeh, 2019: 138). Mikael Naghizadeh dalam tulisannya yang berjudul Rivalry Through Proxies: How Iran and Saudi Arabia Compete for Regional Influence menyatakan bahwa Suriah dan wilayah lainnya seperti Yaman ataupun Bahrain adalah negara yang di dalamnya terdapat proxy kedua negara. Melalui strategi diplomasi ataupun eskalasi militer, baik Arab Saudi dan Iran menyebarkan pengaruh dengan harapan proxy mereka memiliki ketergantungan politik dan ekonomi (Naghizadeh, 2019: 138). Melalui strategi proxy tersebut, Arab Saudi dan Iran dapat melakukan upaya containement dengan menghalangi setiap pengaruh lawannya di kawasan Timur Tengah (Naghizadeh, 2019: 138). Dalam tulisan ini, penulis akan menganalisis bagaimana upaya kedua negara melakukan perimbangan kekuatan melalui proxy-nya di Perang Suriah.

Pokok pembahasan dalam artikel ini adalah untuk melihat bagaimana dua negara seperti Iran dan Arab Saudi melakukan perimbangan kekuatan untuk memenangi kontestasi geopolitik Timur Tengah. Seperti yang dipaparkan oleh 
Jonathan Gelbart dalam penelitiannya yang berjudul The Iran-Syria Axis: A Critical Investigation, Iran dan Suriah telah menjalin suatu hubungan harmonis dan saling tergantung satu sama lain (Gelbart, 2010: 37-40). Melalui penelitian tersebut, rezim Bashar Al-Assad bersinergi dengan pemerintah Iran karena kesamaan ideologi politik, religi dan ekonomi (Gelbart, 2010: 37-40). Bagi Iran, Suriah adalah sekutu dekat sekaligus proxy-nya karena negara tersebut menjadi salah satu tujuan perdagangan negara Mullah tersebut untuk mengatasi embargo dan sanksi ekonomi dari negara Barat (Gelbart, 2010: 37-40). Di satu sisi, Arab Saudi berusaha untuk mengimbangi pengaruh Iran di pemerintahan Bashar Al-Assad melalui dukungan politik bagi tentara pemberontak (Gulcan, 2016: 39-40). Bagi pemerintah Riyadh, pengimbangan kekuatan ini memunculkan harapan agar pengaruh Iran dapat hilang di Suriah. Dengan demikian, Arab Saudi dapat dengan mudah melakukan politik pembendungan di Timur Tengah agar pengaruh Iran memudar (Gulcan, 2016: 39-40). Untuk menjelaskan pola strategi kedua negara tersebut, maka penulis menurunkannya menjadi pertanyaan penelitian mengenai bagaimana upaya perimbangan kekuatan antara Iran dan Arab Saudi untuk memenangi kontestasi geopolitik Timur Tengah melalui Perang Suriah. Pertanyaan penelitian tersebut tentunya akan dijawab melalui metodologi dan pendekatan ataupun teori yang relevan.

Tujuan dari artikel ini pada hakikatnya untuk mengkaji bagaimana strategi Iran dan Arab Saudi mengimbangi kekuatannya satu sama lain untuk memenangkan kontestasi geopolitik Timur Tengah. Mengutip pendapat dari Mehran Kamrava bahwa secara geostrategis Timur Tengah menjadi sentral dari kestabilan dan destabilisasi kawasan lainnya sejak abad pertengahan (Kamrava, 2011: 11). Beberapa penelitian yang dilakukan oleh peneliti hubungan internasional pernah membahas isu tentang perang proxy antara Iran dan Arab Saudi. Pada penelitian yang ditulis oleh Benedetta Berti dan Yoel Guzansky menjelaskan bahwa Iran dan Arab Saudi saling berebut pengaruh di Timur Tengah agar dapat menjadi penguasa tunggal di Timur Tengah (Berti \& Guzansky, 2015: 27-30). Penelitian yang berjudul Saudi Arabia's Foreign Policy on Iran and the Proxy War in Syria: Toward a New Chapter? tersebut bagaimana Arab Saudi menyusun kebijakan luar negerinya dalam membantu tentara pemberontak untuk memenangkan pengaruh mereka terhadap pemerintah Bashar Al-Assad yang berada di bawah kendali Iran (Berti \& Guzansky, 2015: 2730). Perbedaan penelitian tersebut dengan artikel ini adalah analisis yang dikaji oleh Berti \& Guzansky mengkaji dalam studi kebijakan luar negeri. Sedangkan pada penelitian ini, membahas isu proxy Iran dan Arab Saudi dalam pandangan geopolitik. Sedangkan penelitian yang ditulis oleh Buddhika Jayamaha, Jahara Matisek dan William Reno menyatakan bahwa baik Iran maupun Arab Saudi memiliki kepentingan khususnya di Suriah terkait dengan penyebaran pengaruhnya (Jayamaha et al, 2019: 1-8). Dalam penelitiannya yang berjudul The Great Saudi-Iranian Proxy Game mereka menyatakan bahwa kepentingan politik, ekonomi dan sosial berpengaruh dalam perimbangan dua negara tersebut di Suriah (Jayamaha et al, 2019: 1-8). Pada penelitian tersebut, mereka mengkaji secara luas bagaimana Iran dan Arab-Saudi berebut pengaruh untuk dapat menjadi penguasa tunggal di Timur Tengah (Jayamaha et al, 2019: 1-8). Sedikit berbeda dengan apa yang telah dikaji oleh Jayamaha, Matisek \& Reno, permasalahan yang dianalisis dalam artikel ini tidak akan mengkaji strategi proxy antara Iran dan Arab Saudi secara luas, melainkan difokuskan pada studi geopolitik.

\section{Teori Balance of Power: The Pattern of Competition}


Hans J. Morgenthau dalam The Politics Among Nations: The Struggle for Power and Peace (2007) menyinggung terkait pola perimbangan kekuatan yang secara terminologi disebut balance of power. Morgenthau mengatakan bahwa sebuah negara akan melakukan perimbangan kekuatan baik secara langsung maupun tidak langsung (Morgenthau, 2007:192). Perimbangan kekuatan secara langsung dilakukan layaknya Amerika Serikat dan Uni Soviet dengan cara perlombaan senjata ataupun penyebaran pengaruh di wilayah yang ada di dunia (Morgenthau, 2007:192). Namun demikian, kekuatan besar dapat menggunakan sekutu (proxy) untuk mengimbangi lawan politiknya. Pola perimbangan kekuatan melalui proxy ini menitikberatkan pada aspek pihak ketiga yang mana setiap kekuatan besar akan memaksimalkan kapabilitasnya agar pengaruh mereka dapat mengungguli satu sama lain (Morgenthau, 2007:192). Pola tersebut dapat terlihat dari pola di bawah ini:

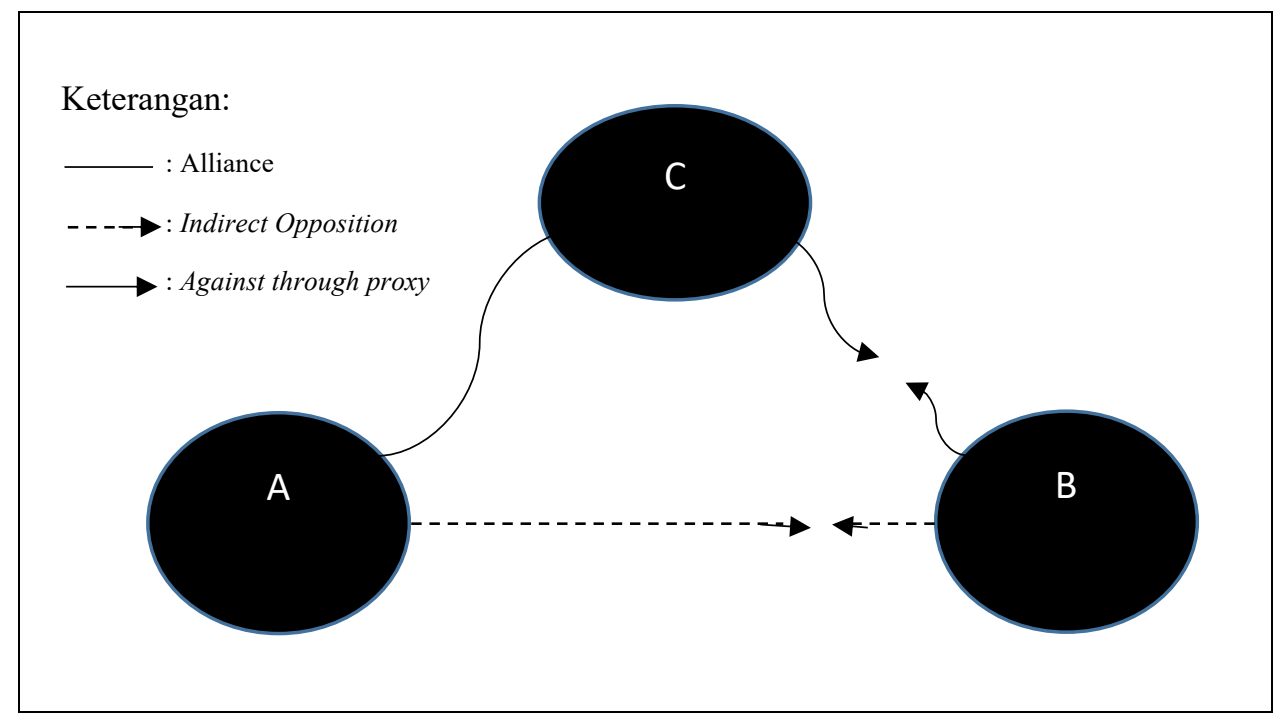

Sumber: Morgenthau, 2007: 194.

Gambar 1. The Pattern of Competition oleh Hans J. Morgenthau

Secara kontekstual, pola perimbangan kekuatan di atas dapat dideskripsikan bahwa negara A memiliki hubungan aliansi dengan negara $C$. Posisi negara $C$ berada di bawah pengaruh negara A yang memiliki kekuatan politik dan ekonomi lebih besar, sehingga negara $\mathrm{C}$ tergantung power yang dimiliki oleh negara A. Di sisi lain, negara B secara tidak langsung memiliki kepentingan perimbangan kekuatan dengan negara $\mathrm{A}$. Morgenthau (2007) menjelaskan bahwa lazimnya pada proxy balancing negara yang memiliki kepentingan perimbangan kekuatan menghindari konfrontasi secara langsung. Akan tetapi, mereka akan memaksimalkan pengaruhnya melalui proxy. Pada kasus dalam artikel ini, Iran dan
Arab Saudi terlibat dalam perimbangan kekuatan. Iran memaksimalkan kekuatannya melalui Suriah yang secara ideologi dan politik berseberangan dengan Arab Saudi. Untuk mengimbangi kekuatan Iran, Arab Saudi memilih membantu tentara pemberontak Suriah sebagai proxy-nya untuk menandingi kekuatan Suriah sekaligus Iran.

Pada praktiknya, perimbangan secara langsung maupun tidak langsung memiliki tujuan yang sama. Pada jurnal yang berjudul Classical Geopolitics, Realism and Balance of Power Theory, praktik perimbangan kekuatan dilakukan oleh negara untuk mencegah intervensi dari rival politik mereka (Wu, 2018: 808). Penelitian yang 
ditulis terkait korelasi antara studi geopolitik dan teori balance of power tersebut menyebutkan bahwa mengimbangi kekuatan negara lain membutuhkan usaha atau tindakan yang strategis (Wu, 2018: 807). Setiap negara akan mencurahkan pengaruh politik, kekuatan militer dan ekonomi serta ideologi untuk mengimbangi rival mereka $(\mathrm{Wu}$, 2018: 807). Terlepas dari bentuk perimbangan tersebut dilakukan secara langsung maupun tidak langsung (proxy), kebijakan tersebut akan memunculkan reaksi yang sama dari rival mereka (Wu, 2018:807). Secara spesifik, upaya memenangkan kontestasi geopolitik di sebuah kawasan membutuhkan sekutu strategis, yang pada praktiknya menjadi perpanjangan tangan sebuah kekuatan besar (Wu, 2018: 813). Meski demikian, upaya proxy atau indirect balancing perlu memerhatikan beberapa hal. Salah satunya, negara perlu melakukan pengelolaan sumber daya politik, militer maupun ekonomi dengan negara yang menjadi proxy mereka (Andersen, 2018: 10). Hal ini tidak lepas dari perlunya mutual trust di antara kedua negara sehingga mereka dapat sejalan dalam implementasi politik luar negeri mereka (Andersen, 2018: 10). Pada intinya, dalam membangun indirect balancing, setidaknya di antara negara yang memiliki kekuatan besar dan negara yang menjadi proxy harus memiliki pandangan serupa terkait ancaman yang dihadapi (Koga, 2018: 640-641). Tanpa adanya sikap ini, negara akan sulit mengimbangi rival mereka melalui proxy karena pada dasarnya "perimbangan" diperuntukkan untuk mengatasi rasa tidak aman dari sebuah ancaman (Koga, 2018: 640-641). Hal lainnya yang perlu ditekankan terkait dengan indirect balancing ini adalah harus ada dua kekuatan yang sama-sama berkompetisi dan berusaha untuk mendapatkan pengaruh dari negara lain (Koga, 2018: 641).

\section{Konsep Geopolitik}

Secara terminologi geopolitik dapat didefinisikan sebagai bentuk analisis dari interaksi antara pengaturan geografis (geographical setting) melalui perspektif pembuat kebijakan politik (Cohen, 2015: 37). Saul Bernard Cohen menjelaskan bahwa geopolitik merupakan perpaduan dari kemampuan politisi memanfaatkan faktor keuntungan geografi untuk kepentingan dan tujuan politik mereka (Cohen, 2015: 37). Mengacu pada kerangka konseptual geopolitik, penulis akan menggunakan tiga struktur yaitu national states, order of national power dan gateway states and regions. Pada aspek national states, negara memiliki peran untuk menjadi pemain utama dalam kontestasi geopolitik apabila mereka mampu memaksimalkan potensi militer, sosial, ekonomi, sumber daya alam, teritorial, dan juga politik (Cohen, 2015: 41-47). Ditinjau dari aspek order of national power, tujuan utama negara secara kontestasi geopolitik terbagi menjadi tiga yaitu major power, regional power, dan meso power (Cohen, 2015: 41-47). Konsep regional power akan digunakan sebagai alat analisis melalui komponen-komponen tradisional yakni populasi, area, sumber daya ekonomi, militer dan teknologi sebagai indikator untuk mengimbangi rival sebuah negara di tataran regional (Cohen, 2015: 41-47). Adapun gateway states and regions merupakan konsep untuk melihat posisi strategis sebuah negara sebagai gerbang masuknya pengaruh kekuatan besar yang pada akhirnya akan menentukan posisi tawar strategis suatu negara di sebuah kawasan (Cohen, 2015: 41-47).

Menarik benang merah antara konsep perimbangan kekuatan dan studi geopolitik memerlukan penjelasan yang lebih mendalam. Menurut Klaus Dodds dalam buku Geopolitics: A Very Short Introduction, perimbangan kekuatan yang membentuk kontestasi geopolitik pernah dan lumrah terjadi pada saat Perang Dingin (Dodds, 2019: 8). Ia menegaskan bahwa 
perimbangan kekuatan pada hakikatnya membagi tatanan geopolitik dunia terpolarisasi dalam dua kekuatan utama dunia (Dodds, 2019: 8). Setiap negara pada hakikatnya memiliki keinginan untuk menyebarkan kekuatan (power) dan pengaruh di setiap wilayah yang ada di dunia (Dodds, 2019:27). Hal ini tentunya selaras dengan konsep arena dalam studi geopolitik yang dikemukakan oleh Colin Flint. Pada buku Introduction to Geopolitics, Flint menjelaskan bahwa sebuah wilayah dikatakan sebagai sebuah arena kontestasi geopolitik yang diperebutkan oleh aktoraktor negara (Flint, 2016:27). Pada tatanan arena, sebuah wilayah akan menjadi arena kontestasi apabila ia dapat meningkatkan power dan posisi sebuah negara menjadi lebih menguntungkan (Flint, 2016:27). Flint menegaskan bahwa ada kecenderungan bagi suatu negara untuk menyebarkan pengaruh dan kekuatannya di sebuah wilayah strategis terutama ketika mereka memandang rival utamanya akan melakukan hal yang sama di wilayah tersebut (Flint, 2016:27). Keuntungan geopolitik yang dicapai oleh negara berkorelasi dengan kemampuan mereka dalam menyebarkan pengaruhnya di suatu wilayah sehingga negara-negara lainnya secara "sukarela" akan menjadi bagian integral dari aliansi mereka (Flint, 2016: 28).

\section{Metode Penelitian}

Penulisan artikel ini akan menggunakan metode kualitatif untuk membedah fenomena HI yang dikaji. Metode kualitatif adalah metode yang dilakukan untuk menganalisis sebuah fenomena kausalitas (sebab-akibat) tanpa menggunakan sarana berpikir ilmiah yang bersifat numerik (Creswell, 2014: 232). Pendekatan metode dalam artikel ini akan menitikberatkan pada pendekatan pragmatis dan positivis. Pendekatan pragmatis memfokuskan artikel ilmiah pada research question yang disajikan (Creswell, 2014: 232). Menurut Creswell
(2014: 232), pendekatan pragmatis memperbolehkan peneliti menggunakan metode baik kualitatif maupun kuantitatif. Adapun pendekatan positivis digunakan dengan cara menyajikan data-data empirik yang otentik untuk mendukung argument peneliti (Creswell, 2014: 234). Terkait teknik penulisan, penulis menggunakan case study untuk menganalisis sebuah fenomena. Teknik studi kasus dalam ilmu sosial digunakan untuk menganalisis proses saling mempengaruhi satu variabel dengan variabel lainnya dalam satu kasus ataupun secara holistik (Roselle \& Spray, 2012: 61). Artikel ini menggunakan pendekatan studi kasus karena penulis berusaha untuk menjelaskan bagaimana kasus upaya perimbangan kekuatan antara Arab Saudi dan Iran berdampak terhadap kontestasi geopolitik di Timur Tengah.

Penggunaan teknik penulisan studi kasus atau case study merupakan sesuatu yang lazim digunakan dalam artikel ilmiah studi hubungan internasional. Seperti yang dijelaskan oleh Laura Roselle dan Sharon Spray dalam Research and Writing in International Relations, studi kasus berusaha untuk menjelaskan fenomena, kasus ataupun isu terkait pengaruh satu variabel kepada variabel lainnya (Roselle \& Spray, 2012: 61). Studi kasus yang dibahas dalam isu-isu hubungan internasional berfokus pada diskursus ekonomi politik, keamanan internasional, kebijakan luar negeri ataupun isu kontemporer hubungan internasional lainnya (Roselle \& Spray, 2012: 61). Terkait pengumpulan data dalam artikel ilmiah yang menggunakan teknik studi kasus, Creswell (2014: 240) membaginya menjadi beberapa cara yaitu observasi, wawancara, dokumen, jurnal ilmiah, data dari lembaga kredibel ataupun dokumen audio visual. Pada penulisan artikel ilmiah ini, penulis menggunakan data sekunder seperti dokumen, jurnal ilmiah ataupun data dari lembaga yang kredibel. Hal ini diperlukan sebagai salah satu penunjang argumen pada tahap analisis. 
HASIL DAN PEMBAHASAN

\section{Aliansi Strategis Iran dan Suriah}

Fenomena Arab Spring yang terjadi pada tahun 2010 merambah hampir ke seluruh kawasan Timur Tengah. Negara seperti Tunisia, Mesir, Bahrain dan bahkan Suriah menjadi salah satu di antara mereka yang terkena dampak dari Arab Spring tersebut. Fenomena terjadi ketika masyarakat melakukan pergerakan sosial dan protes terhadap pemerintahan yang dianggap otoriter (Lynch, 2016: 1-5). Masyarakat Arab saat itu menginginkan adanya keterbukaan (akuntabilitas) dan reformasi politik yang mereka anggap 'menghilang' karena tekanan rezim pemerintah yang otoriter (Lynch, 2016: 15). Suriah mendapatkan hal serupa ketika rakyat mereka yang mayoritas Sunni menentang tekanan dari pemerintahan Bashar Al-Assad yang didukung masyarakat Syiah (Al-Moussawi, 2017: 137-140). Pergolakan yang mengarah pada perang sipil pun tidak terelakkan. Masyarakat Suriah akhirnya terpecah menjadi dua. Iran saat itu memandang bahwa perang sipil tersebut akan berdampak pada kepentingan geopolitik mereka (AlMoussawi, 2017: 137-140). Pemerintah Iran memandang bahwa fenomena Arab Spring dapat menjatuhkan rezim Bashar AlAssad yang didukung Teheran. Apabila rezim tersebut jatuh akibat gerakan Arab Spring, pada akhirnya dapat mengarah pada manuver geopolitik Arab Saudi untuk menancapkan pengaruhnya di Suriah (AlMoussawi, 2017: 137-140).

Pemerintahan Bashar Al-Assad secara politik berhak untuk melakukan hal apapun yang dianggap dapat memulihkan stabilitas keamanan dalam negerinya. Sebagai bagian dari tindakan untuk memulihkan stabilitas politik dan keamanan di Suriah, rezim Bashar Al-Assad melakukan tindakan represif yang pada akhirnya mendapatkan tekanan dari Organisasi Konferensi Islam (OKI) dan Liga Arab (Djalili, 2014: 400401). Suriah mendapatkan tekanan politik dari sesama anggota Liga Arab termasuk
Arab Saudi. Negara tersebut menekan Suriah agar secara kontestasi geopolitik Arab Saudi dapat mengungguli Iran melalui dukungan mereka terhadap tentara pembebasan Suriah (Djalili, 2014: 400401). Agar tetap memiliki pengaruh di Suriah, Iran memberikan dukungan politik terhadap rezim Bashar Al-Assad untuk tetap menjadi pemerintah yang sah (Djalili, 2014: 400-401). Tindakan Iran sesuai dengan pattern of competition yaitu mencoba menanamkan pengaruh pada proxy-nya agar pengaruh Arab Saudi terhadap tentara pemberontak tidak mengancam kepentingan geopolitik mereka di Suriah. Apabila Arab Saudi dapat memaksimalkan pengaruhnya terhadap tentara pemberontak, maka kepentingan geopolitik Iran di Timur Tengah dapat terancam.

Dukungan yang diberikan oleh Iran terhadap proxy mereka, Suriah, tidak hanya dalam bidang politik, tetapi juga militer. Posisi Suriah pada hakikatnya sangatlah strategis bagi Iran. Mereka menjadi salah satu proxy untuk membendung pengaruh Arab Saudi di Timur Tengah (Berti \& Guzansky, 2015: 27-30). Iran memberikan dukungan dengan mengirimkan Al-Quds, pasukan elit Iran di bawah pimpin Jenderal Qassim Suleimani untuk menjadi penasihat militer Suriah (RUSI, 2016: 5). Al-Quds memberikan pelatihan teknis serta pembentukan pasukan paramiliter yang dilatih secara khusus untuk menghadapi pasukan pemberontak Suriah (RUSI, 2016: 5-6). Dalam pandangan Iran, Suriah perlu memiliki kekuatan militer yang mumpuni agar kekuatan pemberontak dapat diredam (RUSI, 2016: 5-6). Bantuan militer yang dilakukan oleh Iran tidak hanya dalam aspek penasihat dan teknis militer, pemerintah Teheran sendiri mengirimkan bantuan persenjataan berupa tank, senapan serbu, senjata anti kavaleri berat dan peluncur misil (RUSI, 2016: 5-6). Perimbangan kekuatan antara Iran dan Arab Saudi sendiri melibatkan aspek intelijen. Pemerintah Iran melalui Ministry 
of Intelligence and Security memberikan bantuan informasi intelijen untuk melumpuhkan basis militer tentara pemberontak (Fulton, 2013). Iran memandang bahwa keamanan dan kestabilan politik di Suriah merupakan sesuatu yang perlu dipertahankan. Negara tersebut memiliki kepentingan politik dan ekonomi terhadap rezim Bashar Al-Assad dalam memenangkan kontestasi geopolitik di Timur Tengah dengan Arab Saudi (AlMoussawi, 2017: 137-140).

Bantuan ekonomi pun diberikan oleh Iran kepada Suriah sebagai bentuk dukungan Teheran terhadap pemerintahan Bashar Al-Assad. Dari aspek ekonomi, Suriah menjadi salah satu negara tujuan ekspor Iran pada saat negara tersebut mendapat sanksi ekonomi dari dunia internasional (Gelbart, 2010: 37-40). Iran melihat bahwa apabila Suriah dapat pulih dari kemelut perang saudara tersebut, kedua negara dapat memaksimalkan perdagangan untuk mencapai kepentingan ekonomi masing-masing (Gelbart, 2010: 3740). Pemberian bantuan ekonomi bagi Suriah oleh Iran salah satunya adalah investasi di bidang energi oleh perusahaan Iran sebanyak 660 juta dolar AS (Financial Tribune, 2017). Selain itu, Iran memberikan kredit khusus sebanyak 3,5 miliar dolar AS dan bantuan suplai minyak mentah sebanyak 660.000 barel (Ozarowski, 2018: 203; Rafizadeh, 2016). Iran mengoptimalkan bantuan tersebut agar Suriah sebagai salah satu proxy utama mereka tidak digulingkan oleh tentara pemberontak yang didukung oleh Arab Saudi. Bantuan ekonomi tersebut ditujukan agar Suriah dapat memulihkan kestabilan ekonomi mereka dari perang saudara yang berkepanjangan.

Iran pada dasarnya berusaha untuk menjadikan Suriah sebagai proxy untuk menjadi salah satu hegemon tunggal di kawasan Timur Tengah. Tidak mengherankan bahwa pemerintah Iran melalui gerakan intelijen dan dukungan politik serta militer terhadap Suriah merupakan langkah strategis mereka dalam mengamankan kepentingan nasional mereka (Price, 2013: 5). Sengketa antara pemerintah Suriah dan tentara pemberontak sejatinya mengancam kepentingan nasional Iran. Kedua negara, yaitu Iran dan Suriah memiliki kesamaan ideologi dan latar belakang sosial-religi (Price, 2013: 5). Terlepas dari itu semua, Iran dan Suriah berada di dalam posisi yang sama dalam memandang ancaman. Pertama adalah kedua negara berada dalam situasi yang tidak menguntungkan karena Iran dan Suriah dianggap sebagai rogue state dalam perspektif negara Barat (Sadjadpour, 2013: 11). Negara Barat seperti Amerika Serikat dan sekutu strategis mereka di Timur Tengah yaitu Arab Saudi dan Israel memposisikan Iran dan Suriah sebagai rival utama dalam mencapai kepentingan nasional mereka di wilayah tersebut (Sadjadpour, 2013: 11). Poin kedua adalah pemerintah Suriah sepenuhnya sangat bergantung sepenuhnya terkait dukungan dana dan militer dari Iran (Sadjadpour, 2013). Salah satu elemen penting dalam politik internasional adalah survive. Rezim Bashar Al-Assad membutuhkan dukungan dari Teheran agar mereka dapat survive menghadapi tekananan dunia internasional. Tanpa adanya dukungan dari pemerintah Iran, maka pemerintah Suriah sudah mengalami kekalahan dalam percaturan politik global (Sadjadpour, 2013: 11).

Posisi Iran sendiri dalam perspektif politik internal Suriah tidak berubah sama sekali. Iran menegaskan bahwa mereka akan tetap mendukung penuh rezim Bashar Al-Assad dari rongrongan tentara pemberontak Suriah (Vohra, 2020). Pengaruh Iran rezim Assad tetap kuat. Salah satunya adalah Iran belum akan menarik mundur kehadiran pasukan militernya dikarenakan rezim Assad masih membutuhkan perlindungan dari Teheran (Vohra, 2020). Terlepas dari perang saudara Suriah yang telah menjalani proses perundingan damai, Iran menjelaskan bahwa kehadiran militernya di Suriah 
merupakan bantuan untuk restrukturisasi kembali militer Suriah yang hancur pasca perang saudara tersebut (DW, 2019). Pemerintah Iran masih menganggap penting kehadiran Suriah sebagai sekutu strategis mereka (Berger, 2020). Pada bidang militer khususnya, warisan dari Jendral Qassim Suleimani yang memberikan dukungan penuh bagi Teheran masih tetap terasa. Untuk menjaga kembali kedaulatan wilayah Suriah yang pecah akibat perang saudara dan gangguan dari ISIS (Islamic State of Iraq and Syria), Iran masih menggantungkan bantuan militer dan intelijennya kepada pemerintah Iran (Berger, 2020). Bagaimanapun juga, di antara kedua negara telah tercipta trust sehingga keduanya saling membutuhkan.

\section{Perimbangan Arab Saudi di Perang Suriah}

Perimbangan kekuatan yang terjadi di Perang Suriah antara Arab Saudi dan Iran berbeda dengan perimbangan kekuatan yang terjadi pada saat Perang Dingin. Reruntuhan perimbangan kekuatan berbentuk proxy terjadi pula di Ukraina antara pemerintah Ukraina dengan tentara pemberontak yang merupakan representasi perimbangan kekuatan antara Rusia dan Barat, khususnya Amerika Serikat (Muhammad, 2015: 6-8). Dunia Barat pun melakukan intervensi kemanusiaan di Suriah walaupun tindakan yang mereka lakukan berbeda dengan apa yang dilakukan di Mesir (Wahyudi, 2018: 5-6). Seperti layaknya Iran yang memberikan dukungan pada proxy mereka di Damaskus, Arab Saudi pun melakukan tindakan yang sama. Sedikit berbeda dengan apa yang dilakukan oleh Iran, Arab Saudi membantu tentara pemberontak dengan memberikan dukungan politik dan militer (Nakamura, 2013: 4-6). Bantuan militer dan politik tersebut tentunya merupakan salah satu upaya untuk membendung perluasan pengaruh Iran di Suriah yang berdampak pada kepentingan geopolitik Arab Saudi.
Perimbangan kekuatan dan pengaruh Arab Saudi dan Iran melalui proxy mereka menjadi sebuah indikator bahwa kedua negara tersebut berusaha untuk menjadi hegemon tunggal di kawasan Timur Tengah. Arab Saudi merespons direct proxy antara Iran dan Suriah dengan menarik mundur duta besarnya dari Damaskus (Nakamura, 2013: 4-6). Arab Saudi dengan kekuatan politiknya di Liga Arab memaksa Suriah untuk bernegosiasi di forum regional (Nakamura, 2013: 10). Negara tersebut memaksa dan menekan secara politik Suriah untuk menghentikan perlawanannya terhadap tentara pemberontak dan mendesak resolusi konflik di antara keduanya (Nakamura, 2013: 10). Tekanan politik Arab Saudi terhadap Suriah di Liga Arab pada akhirnya berhasil menjatuhkan sanksi pembekuan keanggotaan pemerintah Bashar Al-Assad dari Liga Arab (Kucukkeles, 2012: 6-8). Melalui tekanan diplomatik tersebut, Arab Saudi berusaha untuk menekan Suriah sekaligus mengurangi pengaruh Iran di pemerintahan Bashar Al-Assad. Pembekuan keanggotaan tersebut berdampak terhadap pengucilan Suriah dari hubungan multilateral di Timur Tengah (Kucukkeles, 2012: 6-8).

Upaya pengimbangan pengaruh Iran di Suriah dilakukan dengan merespons Suriah secara langsung dan mendukung penuh tentara pemberontak dalam bidang militer. Seperti layaknya Iran yang memberikan dukungan terhadap Suriah, Arab Saudi memberikan bantuan militer berupa 160 unit kargo berupa AK-47, senjata anti-tank dan amunisi lainnya yang dikirim bersama Qatar (Groof, 2013: 38). Arab Saudi pun memanfaatkan kedekatan hubungan luar negerinya dengan Yordania dalam memberikan bantuan 3000 ton ataun 75 unit kargo yang berisi perlengkapan militer (Groof, 2013: 38). Negara Arab Saudi berkolaborasi dengan Yordania dengan menjadikan negara tersebut sebagai salah satu wilayah untuk menyuplai logistik bagi tentara pemberontak (Groof, 2013: 38). Yordania merupakan jalur pintu masuk 
Arab Saudi yang secara geografis berdekatan dengan Suriah (Groof, 2013: 38). Perimbangan yang dilakukan oleh Arab Saudi merupakan bentuk containment dalam menangkal pengaruh Iran di Timur Tengah yang berpotensi mengancam kepentingannya di Timur Tengah. Baik Iran maupun Arab Saudi memanfaatkan proxy mereka sebagai "alat" penyeimbang kekuatan dua negara tersebut. Secara alur, perimbangan kekuatan Arab Saudi dan Iran melalui proxy mereka terangkum dalam gambar di bawah ini:

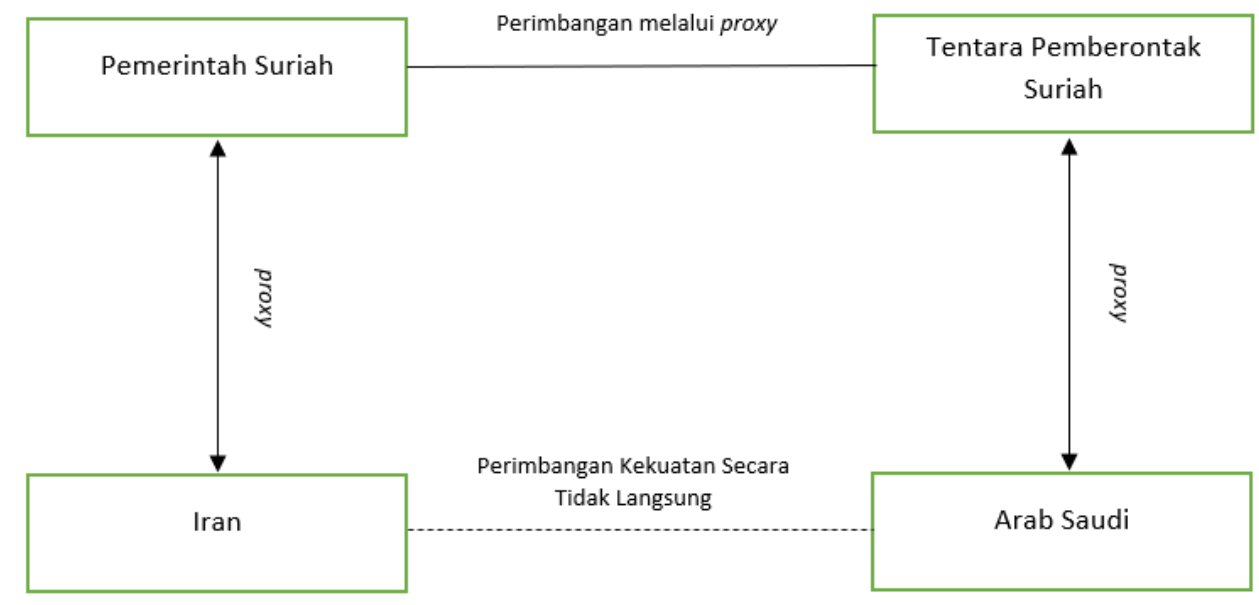

Sumber: Diolah oleh Penulis.

Gambar 2. Proxy Balancing Iran dan Arab Saudi

Berdasarkan diagram di atas, pemerintah Arab Saudi memiliki tiga kepentingan yang hendak dicapai terkait dukungan mereka terhadap tentara pemberontak Suriah. Pada fase awal munculnya perang sipil di Suriah, Arab Saudi memandang bahwa rezim Bashar AlAssad harus diturunkan dari tampuk pemerintahannya (Blanga, 2017). Pemerintah Arab Saudi melihat tentara pemberontak sebagai salah satu penyeimbang pasca jatuhnya Irak dan hubungan bilateral antara negara tersebut dengan Iran kian strategis (Blanga, 2017). Hal ini tidak diinginkan oleh Arab Saudi karena posisi mereka di kawasan Timur Tengah akan dirugikan. Hal tersebut akan berakibat fatal pada kepentingan nasional Arab Saudi. Di sisi lain, dukungan Arab Saudi terhadap tentara pemberontak Suriah seakan menegaskan bahwa negara tersebut secara tidak langsung berseberangan dengan langkah politik luar negeri Iran (Blanga, 2017). Milisi Syiah dan negara yang beraliansi strategis dengan Iran adalah ancaman bagi Arab Saudi (Blanga, 2017). Arab Saudi perlu membendung pengaruh Iran karena keberadaan milisi Syiah tersebut dapat mengancam kedaulatan dan kepentingan nasional Arab Saudi di Timur Tengah (Blanga, 2017). Hal lainnya yang menjadi perhatian Arab Saudi adalah dukungan mereka terhadap tentara pemberontak Suriah merupakan langkah strategis mereka dalam membendung gerakan terorisme seperti ISIS yang menjadikan Suriah sebagai basis perlawanan mereka (Blanga, 2017). Melalui dukungan kepada tentara pemberontak Suriah, Arab Saudi berusaha untuk menjadikan mereka proxy dalam menghadapi gerakan terorisme yang berpotensi menyebar ke negara mereka (Blanga, 2017).

Upaya pembendungan pengaruh Iran yang mendukung penuh rezim Al-Assad dilakukan oleh Arab Saudi dengan berbagai cara. Salah satu strategi yang dilakukan oleh 
Arab Saudi adalah menyokong bantuan finansial dan politik pada suku-suku Arab yang mendiami wilayah Suriah Timur (Dukhan, 2019). Secara etnis, Suriah terdiri dari berbagai macam suku dan bangsa. Etnis Arab setidaknya mendominasi 20 persen populasi penduduk Suriah dan bermukim di wilayah Suriah Timur (Dukhan, 2019). Kesamaan etnis tersebut dimanfaatkan oleh pemerintah Arab Saudi dengan memberikan dukungan finansial dan politik serta menjamin keselamatan mereka dari rezim Al-Assad (Dukhan, 2019). Secara politik, etnis Arab tersebut merupakan kelompok yang tidak mendukung rezim Al-Assad (Dukhan, 2019). Pemerintah Arab Saudi berusaha untuk menjaga hubungan mereka dengan tentara pemberontak dengan tetap membuka pintu donor baik dari aspek finansial, kesehatan maupun politik kepada tentara pemberontak (Awaad, 2020: 6). Tidak hanya itu, Arab Saudi mengajak sekutu mereka di wilayah Teluk dengan mengeluarkan pernyataan doktrinal dari ulama Sunni mereka untuk melawan rezim Al-Assad yang dianggap delusional (Awaad, 2020: 6). Secara etnis dan religi, Arab Saudi memiliki kesamaan dengan sekutu mereka di wilayah semenanjung Arabia seperti Qatar, Uni Emirat Arab ataupun Oman (Awaad, 2020: 6). Melalui pernyataan doktrinal tersebut, Arab Saudi berusaha untuk mempersatukan tidak hanya sekutu mereka di wilayah Teluk, tetapi negaranegara yang memiliki mayoritas penduduk beragama Islam Sunni (Awaad, 2020: 6). Tujuannya adalah menghimpun kekuatan untuk menghadapi rezim Al-Assad dan pemerintah Iran yang mendukungnya.

\section{Kepentingan Geopolitik Iran di Suriah}

Perimbangan kekuatan yang dilakukan oleh Iran dan Arab Saudi memiliki kepentingan politik yang hendak dicapai oleh kedua negara. Tanpa adanya kepentingan politik di antara keduanya, mustahil bagi Iran dan Arab Saudi terlibat dalam perang saudara yang terjadi di
Suriah. Pada awal kemunculannya, Iran telah berambisi menjadi salah satu hegemon di kawasan Timur Tengah (Jahner, 2012: 38-42). Secara ideologi politik, baik Iran dan Arab Saudi, memang bertolak belakang. Arab Saudi cenderung berkiblat pada pemerintah Barat dan Iran memilih untuk merapat ke Rusia (Jahner, 2012: 3842). Ditinjau dari segi identitas dan religi pun mereka berdua berbeda. Iran merupakan pusat dari peradaban Persia yang didominasi Syiah dan Arab Saudi bangga terhadap identitasnya sebagai bangsa Arab serta mengelola dua kota suci besar umat Islam yang didominasi Sunni (Jahner, 2012: 38-42). Rivalitas kedua negara tersebut berdampak terhadap dinamika geopolitik di kawasan Timur Tengah.

Bagaimana sejatinya posisi Suriah dalam perspektif Iran? Mengacu pada konsep national power yang diusung oleh Cohen, aktor negara dapat memaksimalkan kekuatan politik, militer maupun teritorialnya untuk dapat memenangi pengaruh dalam dinamika geopolitik sebuah kawasan (Cohen, 2015: 41-47). Suriah memiliki nilai strategis bagi Iran terutama sebagai negara penghubung untuk mengakses logistik dan kepentingan ekonomi mereka mulai dari Teluk Persia hingga Laut Tengah (Nasur, 2014: 84-85). Di satu sisi, bila Iran dapat memainkan pengaruhnya maka negara tersebut dapat mengisolasi manuver politik luar negeri Arab Saudi di kawasan Timur Tengah. Mengacu pada konsep order of national power, pencapaian sebuah negara dalam menancapkan pengaruhnya dalam dinamika geopolitik di sebuah wilayah adalah memaksimalkan kekuatan politik, militer maupun ekonomi (Cohen, 2015: 4147). Iran sendiri menduduki peringkat ke 14 sebagai salah satu negara dengan kekuatan militer terbanyak di dunia. Berdasarkan data yang diperoleh dari Global Firepower (2020), Iran setidaknya memiliki 523.000 personil militer dengan dukungan 155 pesawat tempur, 2.056 tank, 
tujuh frigate dan 34 kapal selam. Kekuatan militer tersebut dipergunakan Iran untuk menjaga proxy mereka di Suriah.

Posisi strategis Suriah dalam wilayah Timur Tengah memiliki nilai politis dalam kepentingan geopolitik Iran. Pemerintahan Bashar Al-Assad memiliki kedekatan secara politik dengan Iran. Selain kesamaan visi misi mereka dalam memandang ancaman ideologi seperti Israel dan Amerika Serikat, Iran dan Suriah disatukan dalam identitas religi (Jahner, 2012: 38-42). Mengacu pada konsep gateway states and regions, Suriah dalam perspektif Iran merupakan pintu masuk untuk menancapkan pengaruhnya di wilayah Timur Tengah. Kekuatan militer dan politik yang dimiliki oleh Iran tidak terlepas dari keingan mereka untuk menjadi salah satu hegemon di Timur Tengah (Mustahyun, 2017). Ditinjau dari aspek geografis, posisi Suriah yang berbatasan dengan Laut Tengah dan berada di sebelah Utara negara Arab Saudi memungkinkan Iran untuk mengisolasi manuver politik rival mereka. Terlebih lagi, Iran sendiri telah memiliki pengaruh yang cukup besar di dalam pemerintahan Irak dan Hisbullah di Lebanon (Mustahyun, 2017: 92-93). Kepentingan geopolitik Iran lainnya terhadap Suriah adalah negara tersebut dapat menjadi proxy mereka dalam membendung tekanan dunia internasional khususnya dari negara Barat (Shujahi \& Shafiq, 2018: 144). Terlepas dari kesamaan politik maupun identitas religi, Suriah dapat dikatan menjadi batas terluar untuk melawan rival mereka yang berada di wilayah Teluk seperti Arab Saudi (LSE, 2018: 9-10). Apabila Suriah jatuh ke dalam pengaruh Arab Saudi, Iran akan terancam tidak hanya oleh rival mereka di Timur Tengah, melainkan juga sekutu Arab Saudi seperti Amerika Serikat.

\section{Posisi Suriah dalam Perspektif Arab Saudi}

Keberadaan Suriah memiliki nilai yang strategis dalam perspektif Arab Saudi sama seperti Iran memandang negara yang berada di bawah pemerintahan Bashar AlAssad. Seperti yang telah dipaparkan pada penjelasan sebelumnya, bantuan militer, ekonomi maupun politik kepada tentara pemberontak Suriah tidak terlepas dari upaya mereka untuk melemahkan rezim AlAssad. Rivalitas Iran dan Arab Saudi tidak hanya menyangkut aspek politik melainkan pula identitas. Hal ini terjadi karena kedua negara tersebut memiliki rivalitas etnis dan agama yang menjadi salah satu pemicu perimbangan kekuatan di wilayah Timur Tengah (Jahner, 2012: 38-42). Apabila ditinjau dari segi politik pun, Arab Saudi dan Iran berseberangan. Iran dan Suriah merupakan dua negara di Timur Tengah yang memandang negara Barat sebagai sebuah ancaman (Tan \& Perudin, 2019: 23). Pada saat yang bersamaan, Arab Saudi memiliki hubungan strategis dengan negara Barat seperti AS dalam membangun kekuatan militer mereka di wilayah Timur Tengah (Tan \& Perudin, 2019: 2-3). Kedekatan yang terjalin antara Arab Saudi dan AS secara tidak langsung menjadi pemicu perebutan pengaruh di dalam konflik Suriah itu sendiri.

Iran sebenarnya telah terlebih dahulu memiliki pengaruh di Suriah. Pengaruh tersebut setidaknya dapat menghalangi kepentingan geopolitik Arab Saudi di Timur Tengah, khususnya dalam membendung manuver politik Iran (Shujahi \& Shafiq, 2018: 144). Apabila Iran semakin kuat menancapkan pengaruhnya di Timur Tengah, Arab Saudi akan mengalami kesulitan dalam mengimbangi pengaruh Iran di kawasan Arab Levant (LSE, 2018: 910). Kepentingan geopolitik Arab Saudi di Timur Tengah dapat mengisolasi manuver politik mereka (LSE, 2018: 9-10). Posisi Suriah bagi Arab Saudi memiliki aspek strategis seperti layaknya Iran memandang Suriah. Ketika Suriah jatuh ke dalam pengaruh Iran, Arab Saudi hanya mengandalkan sekutunya seperti Yordania dalam membendung pengaruh Iran di wilayah Levant atau Syam (Jayamaha, et. Al., 2019: 7-8). Arab Saudi kini hanya 
mengandalkan bantuan dari Amerika Serikat yang merupakan rival Iran dan negara-negara Teluk seperti Qatar, Bahrain, Uni Emirat Arab dan Oman (Jayamaha, et. Al., 2019: 7-8). Sedangkan Yaman yang dulu merupakan sekutu strategis Arab Saudi dilanda ketidakstabilan akibat perang saudara yang melibatkan etnis Houthi yang bermahzab Syiah serta mendapat dukungan penuh dari Iran (Jayamaha, et. Al., 2019: 78). Oleh karenanya, Arab Saudi berusaha selayaknya Iran untuk memiliki pengaruh di Suriah.

Konflik Suriah sejatinya menjadi suatu pembuka bahwa pergulatan dinamika geopolitik di kawasan Timur Tengah sudah sedemikian rumit. Suriah menjadi sebuah arena bagi kekuatan besar baik di kawasan regional maupun di luar regional untuk memenangkan kontestasi geopolitik (Tan \& Perudin, 2019: 2-3). Suriah merupakan miniatur dari dinamika geopolitik Timur Tengah yang terbagi menjadi dua faksi (Tan
\& Perudin, 2019: 2-3). Arab Saudi melihat bahwa kolaborasi Iran dengan negara seperti Suriah, Irak, Lebanon maupun pemberontak Houthi akan mengakibatkan posisi mereka terancam dan terkucilkan di kawasan Timur Tengah (Tan \& Perudin, 2019: 2-3). Arab Saudi melakukan hal yang sama seperti Iran dengan membangun aliasi dengan negara Arab Teluk seperti Qatar, UAE, Bahrain maupun Yordania (Tan \& Perudin, 2019: 2-3). Tujuannya tetap sama yaitu memenangkan kontestasi geopolitik di Timur Tengah agar Arab Saudi dapat mengungguli rival utama mereka yaitu Iran. Keterlibatan Arab Saudi terutama dukungan mereka kepada tentara pemberotak Suriah merupakan sebuah indikasi bahwa negara tersebut tidak ingin diungguli dari segi kekuatan politik dan militer di kawasan Timur Tengah. Dampak perimbangan tersebut pada akhirnya memecah peta kekuatan di Timur Tengah seperti yang terlihat dari gambar berikut: 


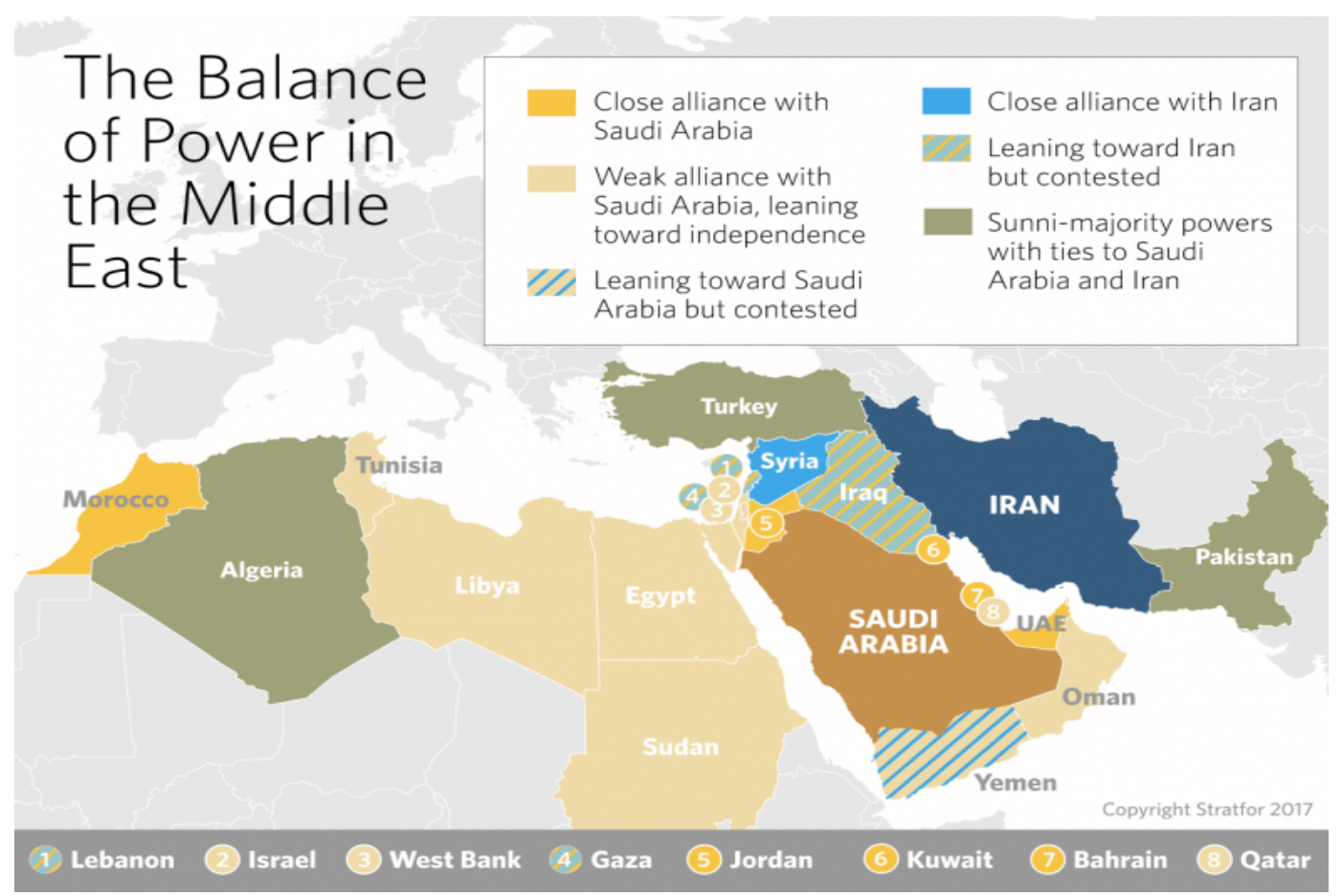

Sumber: Worldview Stratfor, 2018.

Gambar 3. Peta Perimbangan Kekuatan di Timur Tengah

\section{KESIMPULAN}

Perimbangan kekuatan antara Iran dan Arab Saudi melalui perang saudara di Suriah merupakan ajang bagi keduanya untuk menyebarkan pengaruh dan memenangkan kontestasi geopolitik di Timur Tengah. Iran terlibat dan mendukung pemerintahan Bashar Al-Assad untuk tetap berkuasa di Suriah. Terlepas dari kesamaan ideologi dan identitas religi, Iran memandang bahwa Suriah merupakan negara strategis untuk mengisolasi rival utama mereka di Timur Tengah, yaitu Arab Saudi. Begitu pun Arab Saudi yang mendukung tentara pemberontak Suriah yang ingin menggulingkan rezim Bashar Al-

\section{Daftar Pustaka}

\section{Buku}

Andersen, M. S. (2018). Balance of Power. Dalam Gordon Martel (eds), The Encyclopedia of Diplomacy. USA: John Wiley \& Sons.

Burdah, I. (2008). Konflik Timur Tengah: Aktor, Isu dan Dimensi Konflik. Yogyakarta: Tiara Wacana.
Assad. Secara identitas, tentara pemberontak bermahzab Sunni dan dekat dengan identitas religi Arab Saudi. Namun, dukungan Arab Saudi pada tentara pemberontak memiliki muatan politik yaitu menggulingkan pemerintah Bashar AlAssad yang bermitra dengan Iran. Tujuan utamanya adalah memotong akses logistik antara Teluk Persia dan Laut Tengah yang dapat menguntungkan Iran secara geopolitik. Dengan demikian, dapat disimpulkan bahwa keterlibatan Iran dan Arab Saudi pada dasarnya merupakan ajang untuk mengimbangi kekuatan masing melalui proxy mereka.

Creswell, J. (2014). Research Design: Qualitative, Quantitative and Mixed Methods Approaches ( ${ }^{\text {th }}$ Eds). London: SAGE.

Cohen, S. B. (2015). Geopolitics: The Geography of International Politics ( $3^{\text {rd }}$ ed). Third Edition. London: Rowman \& Littlefield. 
Dodds, K. (2019). Geopolitics: A Very Short Intrdouction. United Kingdom: Oxford University Press.

Fawcett, L. (2016). International Relations of The Middle East (4th ed). England: Oxford Press.

Flint, C. (2016). Introduction to Geopolitics $\left(3^{r d} E d\right)$. New York: Routledge.

Groof, M. (2013). Arms Transfers to the Syrian Arab Republic: Practice and Legality. Brussels: GRIP.

Kamrava, M. (2011). The Modern Middle East: A Political History Since World War 1. Berkeley: University of California Press.

Kucukkeles, M. (2012). Arab League's Syrian Policy. Washington D.C: SETA.

Lynch, M. (2016). The New Arab Wars: Uprisings and Anarchy in the Middle East. USA: Public Affairs.

LSE. (2018). Saudi Arabia and Iran: Beyond Conflict and Coexistence. United Kingdom: Middle East Centre.

Morgenthau, H. (2007). Politics Among Nations. New York: McGraw-Hill.

Oktorino, N. (2015). Pedang Sang "Khalifah": ISIS dan Ancaman Radikalisasi dalam Perang Saudara di Suriah dan Irak. Jakarta: PT Elex Media Komputindo.

Roselle, L, \& Spray, S. (2012). Research and Writing in International Relations. Boston: Pearson Longman.

RUSI. (2016). Understanding Iran's Role in the Syrian Conflict. London: Royal United Service Institute for Defence and Security Studies.

\section{Jurnal}

Al-Moussawi, A. H. (2017). Iran and the Syrian Crisis. Journal of US-China Public Administration, 14(3), 136144.

Awaad, A.F. (2020). Iranian Saudi rivalry over the regional role: Syria as a model. Review of Economics and Political Science, 1-19.

Berti, B. \& Guzansky, Y. (2015). Saudi Arabia's Foreign Policy on Iran and the Proxy War in Syria: Toward a

New Chapter? Israel Journal of Foreign Affairs, 9(3), 25-34.

Djalili, M. (2014). Iran's Syria policy in the wake of the 'Arab Springs'. Turkish Review, 4(4), 396-405.

Gelbart, J. (2010). The Iran-Syria Axis: A Critical Investigation. Stanford Journal of International Relations, $X I I(1), 36-42$.

Gulcan, P. (2016). From Stillness to Aggression: The Policy of Saudi Arabia towards Syria after the Arab Spring. International Journal of Humanities and Social Science, 6(9), 39-42.

Jahner, A. (2012). Saudi Arabia and Iran: The Struggle for Power and Influence in the Gulf. International Affairs Review, XX(3), 38-50.

Jayamaha, B., et al. (2019). The Great SaudiIranian Proxy Game. Middle East Quaterly, 1-10.

Koga, K. (2018). The Concept of "Hedging" Revisited: The Case of Japan's Foreign Policy Strategy in East Asia's Power Shift. International Studies Review, 20(4), 633-660.

Muhammad, A. (2015). "Selamat Datang Perang Dingin!” Kepentingan Rusia Di Krimea Dan Ukraina Timur Dan Ketegangan Hubungan dengan Barat. Insignia: Journal of International Relations, 2(02), 01-11. Mustahyun. (2017). Rivalitas Arab Saudi Dan Iran di Timur Tengah dalam Arab Spring Suriah Tahun 20112016. Islamic World and Politics, 1 (1), 90-110.

Nakamura, S. (2013). Saudi Arabian Diplomacy During the Syrian Humanitarian Crisis: Domestic Pressure, Multilateralism, and Regional Rivalry for an Islamic State. Journal of Tumnoil and Japanese Respon, 13(2), 1-30.

Nasur, B. (2014). Syria-Iran Relations (2000-2014). International Journal of Humanities and Social Science, 4(2), 80-88. 
Ozarowski, R. (2018). Iran's Engagement in Syrian Conflict. Causes and Consequences. Przegląd Strategiczny, 11, 201-210.

Price, B. (2013). Syria: A Wicked Problem for All. CTC Sentinel, 6(8), 1-6.

Sadjadpour, K. (2013). Iran's Unwavering Support to Assad's Syria. CTC Sentinel, 6(8), 11-13.

Shujahi, F. K., \& Shafiq, M. (2018). Evaluating Iran-Saudi Strategic Competition in Middle East: Implications for Regional Security. National Defense University Journal, 142-149.

Tan, K. H., \& Perudin, A. (2019). The Geopolitical Factor in The Syrian Civil War: A Corpus Based Thematic Analysis. SAGE Journal, 9(2), 1-15.

Wahyudi, H. (2018). Standar Ganda Politik Luar Negeri Amerika Serikat Terhadap Kudeta Mesir 2013. Insignia: Journal of International Relations, 5(1), 1-14.

Wu, Z. (2018). Classical Geopolitics, Realism and The Balance of Power Theory. Journal of Strategic Studies, 41(6), 786-823.

\section{Artikel Daring}

BBC. (2017). “Apa yang melatarbelakangi perselisihan Arab Saudi dan Iran?"

Diakses dari

https://www.bbc.com/indonesia/du nia-42036425.

Berger, M. (2020). "Qasem Soleimani helped shape the brutality of the Syrian war." Diakses dari https://www.washingtonpost.com/w orld/2020/01/03/qasem-soleimanihelped-shape-brutality-syrian-war/.

Dukhan, H. (2020). "Syria: attempts by Saudi Arabia, Iran and Turkey to coopt Arab tribes will deepen the country's divisions." Diakses dari https://theconversation.com/syriaattempts-by-saudi-arabia-iran-andturkey-to-co-opt-arab-tribes-will- deepen-the-countrys-divisions119402.

DW. (2019). "Syria conflict: What do the US, Russia, Turkey and Iran want?"

Diakses dari https://www.dw.com/en/syriaconflict-what-do-the-us-russiaturkey-and-iran-want/a-41211604.

Financial Tribune. (2017) "New Page in Iran-Syria Economic Relations." Diakses dari https://financialtribune.com/articles /economy-business-andmarkets/57826/new-page-in-iransyria-economic-relations.

Fulton, W. H. (2013). "Iranian Strategy In Syria." Diakses dari

Understandingwar.org:http://www.u nderstandingwar.org/sites/default/fi les/IranianStrategyinSyria-1MAY.pdf. Global Firepower. (2020). "2020 Military Strength Ranking." Diakses dari https://www.globalfirepower.com/c ountries-listing.asp.

Naghizadeh, M. B. (2019). "Rivalry Through Proxies: How Iran and Saudi Arabia Compete for Regional Influence." Diakses dari https://www.researchgate.net/public ation/335841432_The_Great_SaudiIranian_Proxy_Game/link/5d7fbac84 58515fca16dbc11/download.

Rafizadeh, M. (2016,). "Implications of the growing Iran-Syria economic relations." Diambil dari http://english.alarabiya.net/en/view s/news/middleeast/2016/09/30/How-Iran-isgradually-owning-Syriaeconomically.html.

Robehmed, S. (2013). "Bombs and guns 'have killed 11,500 children' in Syria, research shows, including some executed and tortured." Diakses dari http://www.independent.co.uk/news /world/middle-east/bombs-andguns-have-killed-11500-children-insyria-research-shows-including- 
some-executed-and-tortured8960809.html.

SOHR. (2018). "Syria: Events of 2018." Diakses dari https://www.hrw.org/worldreport/2019/country-chapters/syria.

Vohra, W. (2020). “Suleimani's Absence Has Been No Problem for Iran in
Syria." Diakses dari

https://foreignpolicy.com/2020/04/

03/suleimani-iran-syria-influenceirgc-no-problem/.

Worldview Stratfor. (2018). “2018 Annual

Forecast.” Diakses dari

https://worldview.stratfor.com/articl e/2018-annual-forecast. 